\title{
Modalidade 1:1: Tecnologia Individual Possibilitando Redes para Aprendizagem de Fluência Digital
}

\section{Daniela Stevanin Hoffmann}

Orientadora: Profa. Dra. Léa da Cruz Fagundes

Coorientador: Prof. Dr. Marcus Vinícius de Azevedo Basso

Banca: Profa. Dra. Rosa Maria Vicari (PPGIE/UFRGS), Prof. Dr. Júlio Alberto Nietzke (UFRGS), Profa. Dra. Débora Pereira Laurino (FURG)

Data da defesa: 29 de abril de 2011

Alunos, professores, gestores, pesquisadores universitários, objetos tecnológicos, arquivos, registros, habilidades, ... são os nós que compõem a grande rede tecida na experiência piloto do Projeto Um Computador por Aluno na Escola Estadual de Ensino Fundamental Luciana de Abreu de Porto Alegre no Rio Grande do Sul onde foi desenvolvida a presente pesquisa. O problema central desta investigação é compreender como se dá a constituição de uma Rede de Fluência Digital a partir do trabalho com Projetos de Aprendizagem mediado pela tecnologia individualmente disponível na modalidade 1:1. A fim de identificar as relações entre a implementação da proposta pedagógica e a prática da modalidade 1:1 na escola, foram definidas três redes: a Rede de Atores, formada pela comunidade da escola Luciana de Abreu e pesquisadores do Laboratório de Estudos Cognitivos da Universidade Federal do Rio Grande do Sul (LEC), atuando em uma pesquisa-ação; a Rede de Recursos, composta pelo laptop educacional XO e o ambiente virtual de aprendizagem AMADIS; e a Rede de Fluência Digital, resultado da interação entre estas redes. A abordagem teórico-metodológica que subsidia a elaboração do problema e a análise dos dados é a Epistemologia Genética. Desenvolveu-se um estudo de caso cuja unidade de análise foi a Rede de Atores que apresentou como evidências os arquivos dos laptops e os registros do histórico do ambiente virtual de um grupo de dez alunos da Rede de Atores e o diário de campo da observação participante da pesquisadora do LEC, autora desta investigação. Foram elaborados, a partir das evidências, Identificadores e Períodos Singulares da Rede de Fluência Digital, que auxiliaram na Identificação de peculiaridades e na Caracterização dos períodos singulares na constituição da Rede de Fluência Digital. Estabelecendo relações entre o conceito de Fluência Digital de Ba, Tally \& Tsikalas (2002) e estas duas etapas da análise foram criadas as Categorias da Rede de Fluência Digital que permitiram, com o processo de Categorização da constituição da Rede de Fluência Digital, compreender que a Rede de Fluência Digital se deu pelo desenvolvimento de condutas cognitivas constituídas de meios elaborados pelos sujeitos da Rede de Atores para solucionar os problemas com os quais se deparavam quando em interação com a Rede de Recursos. Entende-se que este trabalho contribui para a área da Informática Educativa nos estudos relacionados à implementação da modalidade 1:1 nas escolas, à fluência digital, à vinculação entre prática pedagógica e Tecnologias da Informação e Comunicação e a teorizações sobre possíveis relações entre estas e a Epistemologia Genética. Propõe-se dar continuidade a investigações relacionadas à modalidade $1: 1$ voltadas à formação de professores.

Palavras-chave: Fluência digital. Redes. Laptop educacional. Modalidade 1:1. Tecnologias da informação e comunicação.

Referência:

HOFFMANN, Daniela Stevanin. Modalidade 1:1: Tecnologia Individual Possibilitando Redes para Aprendizagem de Fluência Digital. Orientadora: Léa da Cruz Fagundes. Coorientador: Marcus Vinícius de Azevedo Basso. 2011. Tese (Doutorado) - Programa de Pós-Graduação em Informática na Educação, Centro de Estudos Interdisciplinares em Novas Tecnologias da Educação, Universidade Federal do Rio Grande do Sul, 2011, Porto Alegre, BR-RS. Membros da Banca Examinadora: Rosa Maria Vicari (PPGIE/UFRGS), Júlio Alberto Nietzke (UFRGS), Débora Pereira Laurino (FURG). Data da defesa: 29/04/2011. 